\title{
An Investigation on Customers' Selection on Wealth Management Services: Evidence from Taiwan
}

\author{
Hsin-Hue, Chang ${ }^{\text {a, }}$, Min-Li, Yao ${ }^{\text {b }}$ \\ ${ }^{a}$ b Department of Finance, Ming Chuan University, 250 Zhong-Shan N. Rd., Sec.5. Taipei, Taiwan \\ *Corresponding Author: hhchang@ mail.mcu.edu.tw
}

\begin{abstract}
We use a face-to-face interview to execute a two-stage questionnaire survey and employ both exploratory factor analysis (EFA) and confirmatory factor analysis (CFA) to measure factors influencing customers' selection of WM services. The results of EFA suggest three factors, which are brand image, perceived value, and financial consultants' service quality, can influence customers' selection of WM services. A second-order CFA suggests that brand image, perceived value, and financial consultants' service quality (three first-order factors) significantly, positively affect overall customers' satisfaction (a second-order factor). In addition, the moderating analysis result shows that married and single groups have slightly different views on selecting a WM provider. We believe that once service providers understand what are the key factors that impact customer's selection decision, they can based on this study result to develop a set of marketing strategies which satisfied customers' needs and maximize its market shares.
\end{abstract}

Keywords: Brand Image, Perceived Value, Consultants' Service Quality.

\section{Introduction}

Since Financial Supervisory Commission (FSC) in Taiwan published compliance guidelines for the banks offering wealth management (henceforth, WM) services in 2005, domestic banks have aggressively developed their private WM services and have succeeded in creating huge commission income. The financial crisis in 2008 had great impact on a lot of customers not only the wealth but also the investing philosophy. Those customers relied on WM services claimed that banks did not do their best to manage their assets and complained that bank's financial consultants did not explicitly demonstrate the risk level of the financial products. From WM providers' point of view, how to retrieve the trust of customers becomes extremely important if they want to regain in the market. By understanding what the customers want and need are critical to be succeeded because those critical points play an important role during the process of selecting WM services. Therefore, the aim of this study is to investigate key factors that influence customers to choose a WM provider.

Recently, Chan and Chan (2011) use the theory of planned behavior (TPB) to identify the factors and attitudinal preferences that influence Taiwanese customers who reside in China to select a WM provider. Results show that "feeling of trustworthiness", "provision of flexible services" and "feeling of cultural affinity" are the most crucial items that impact their selection decision in terms of WM services. They conclude that "guan-xi" plays an important role during the marketing process of WM services. In addition, by using an analytic hierarchy process (AHP) approach, Yu and Ting (2011) employ image, products, and service quality to investigate factors influencing Taiwanese customers' selection of WM services. They find out that customers' first concern about the WM services is service quality, followed by the products and the image.

Many of WM providers were claimed and lost their reputation during the financial crisis in 2008. While the reputation is closely associated with the brand image and as identified earlier as one of the customers' concerns; follow prior studies (e.g., Smith et al., 2010; Yu and Ting, 2011), we investigate the effect of brand image on customer's selection of a WM provider. As suggested by $\mathrm{Yu}$ and Ting (2001), product characteristics (e.g., risk, return, fees) might influence customers' selection of WM services. 
However, most WM providers are able to offer very similar products and services because they are easy to be duplicated or copied. Therefore, we highlight on the perceived value rather than on the product characteristics (e.g., Al-Hawari et al., 2005; Soureli et al., 2008). Perceived value is defined as consumers' judgment about a product's overall excellence or superiority by Zeithaml (1988)

Financial consultants basically represent banks to perform WM functions and personally contact with customers. Their performance and service quality are directly evaluated by the customers. Indeed, it is very common that when financial consultants move to another financial institution, customers follow with them and switch their account to that institution, too. This implies financial consultants' service quality might be a key factor that influences WM development for banks because good service quality results in good connection (guan-xi). Therefore, we pick financial consultants' service quality rather than bank's service quality in our study. This study thus uses dimensions consisting of brand image, perceived value, and financial consultants' service quality to investigate factors influencing Taiwanese customers' selection of WM services.

We execute two-stage questionnaire and briefly employ an exploratory factor analysis (henceforth, EFA) and a confirmatory factor analysis (henceforth, CFA) to measure factors influencing customers' selection of WM services. The empirical results from EFA extract three factors: brand image, perceived value, and financial consultants' service quality, and those factors are also identified by CFA. The second-order CFA result further suggests that brand image, perceived value, and financial consultants' service quality as first-order factors can significantly, positively affect the second-order factor, which can be used to represent overall customers' satisfaction (Chang et al., 2004; Li et al., 2008). Furthermore, the moderating analysis finds that marital status influences the selection of WM services while gender does not.

Our research offers several substantial contributions. First, unlike previous studies using banks' service quality, we highlight the financial consultants' service quality because the relationship between financial consultants and WM customers is more direct and close, especially in East Asian markets. Therefore, it is necessary to differentiate financial consultants' service quality from banks' service quality to understand the role of financial consultants in East Asian WM market. Second, we adopt appropriate methodology to conduct the empirical analyses. Two set of questionnaires and two factor analyses (an EFA and a CFA) are employed to measure factors influencing customers' selection of WM services. A second-order CFA model suggests that customers' overall satisfaction can be measured by brand image, perceived value, and consultants' service quality. Third, based on the empirical results, we highlight some strategic implications that might help customers select a WM provider and assist WM providers in promoting their financial products and services. To best of our knowledge, fewer studies have been done in investigating factors influencing customers' selection of WM services in Asian markets. Our study attempts enrich the literature, and the results have implications for banks developing marketing strategies in WM services territory.

The study is organized as follows: section 2 reviews the theoretical background and forms factor constructs for the study, section 3 describes the estimation and questionnaire procedures, section 4 illustrates the empirical results, and section 5 offers concluding remarks and strategy implications.

\section{Literature Review and Hypotheses Development}

\subsection{Brand image}

Marketing studies consider a brand as clusters of associations in consumers' minds, adding value to consumers' experience and hence driving their positive reactions toward the company (Keller, 1993). Brand image influences consumers' purchasing behavior, especially when it is difficult to differentiate products or services on the basis of tangible features (Mudambi et al., 1997). In addition, behavioral finance studies argue that brand image is a heuristic that drives investors to make investment decisions (Barber and Odean, 2008). A line of behavioral finance studies have indicated that individual customers prefer to invest in stocks with big (brand) name because they might consider that a great company is a good stock (Statman et al., 2008; Filbeck et al., 2013).

A positive brand image can strengthen consumers' confidence in a company, and further build loyalty. Many studies reveal in the real business practice, when customers feel that financial products are associated with potentially high perceived risk, the role of a positive brand can act as a risk-reducing device in reassuring the consumers (de Chernatony and Dall'Olmo Riley, 1999; de Chernatony and 
Cottam, 2006). A line of study results from behavioral finance state that media can improve firm's brand image, which induces investors to invest in the recommended stocks without caution (Filbeck et al., 2013). Besides, according to $\mathrm{Yu}$ and Ting (2001), banks with higher level of professional image can strengthen customers' trust. Therefore, brand image can be built via media. Many WM providers invest huge money in the advertisement. Through the media broadcasting, their name becomes even bigger and "professional image" being window dressed. Our study thus assumes that bank image is an important factor that influences customers' selection of WM services.

H1: Brand image influences customers' selection of WM services

\subsection{Perceived value}

Zeithaml (1988) indicates that perceived value can be defined as consumers' judgment about a product's overall excellence or superiority, and he defines value into four groups: (1) value is low price, (2) value is what I want in a product, (3) value is the quality I get for the price I pay, and (4) value is what I get for what I give. Consequently, perceived value consists of low price, utility, and the trade-off between give (price) and get (quality). Behavioral finance indicates that mental accounting may influence consumers' (investors') decision. Thaler (1985) classifies consumers' utility into different accounts, consisting of acquisition utility and transaction utility. Acquisition utility represents the pleasure from obtaining a good, and transaction utility derives from a comparison of actual prices with reference point such as the regular price.

Al-Hawari et al. (2005) reveal that customers' perceived price quality (i.e., perceived value) can be accounted for service charge, acceptable fees, and competitive fees. By using a structural equation model (SEM), Soureli et al. (2008) investigate factors that influence customers' cross-buying in the financial industry. They find that perceived value directly influences customers' satisfaction and indirectly impacts the intention to cross-buying. Thus, we assume that perceived value influences customers' selection of WM services. Therefore:

$\mathrm{H} 2$ : Perceived value influences customers' selection of WM services

\subsection{Financial consultants' service quality}

Parasuraman et al. (1988) suggest a disconfirmation model by using five dimensions which are reliability, responsiveness, assurance, empathy, and tangibles to measure customers' perceived service quality. Based on the disconfirmation model, service quality is the comparison of expectations and perceptions of the service. The score difference between these two measures represents service quality. Chan and Chan (2011) indicate that Taiwanese customers who reside in China like to choose WM providers from home country due to "provision of flexible services". Yu and Ting (2011) use attitude, communication, confidentiality, and convenience to measure service quality in Taiwan's WM industry and find that communication and convenience are the two most important items for them to choose a WM provider. Since customers mainly and directly contact with their financial consultants, it is necessary to highlight on financial consultants' service quality instead of on banks' service quality. We thus adopt the financial consultants' services quality (CSQ) as a criterion influencing customers' selection of WM services. The hypothesis is shown as follows:

H3: Financial consultants' services quality influences customers' selection of WM services

\section{Methodology}

\subsection{The Conceptual Framework}

Based on the prior research, we mainly use three criteria (factors): brand image (BI), perceived value (PV), and consultants' services quality (CSQ) to examine if they are the key criteria influencing customers' selection of WM providers. We employ a second-order CFA to represent the conceptual model, shown in Figure 1. The BI, PV, and CSQ are first-order factors, which are used to explain or represent the second-order factor (SAT). In addition, we use gender and marital status as moderating variables to investigate if gender and marital status influence the relationships between second-order factor and first-order factors.

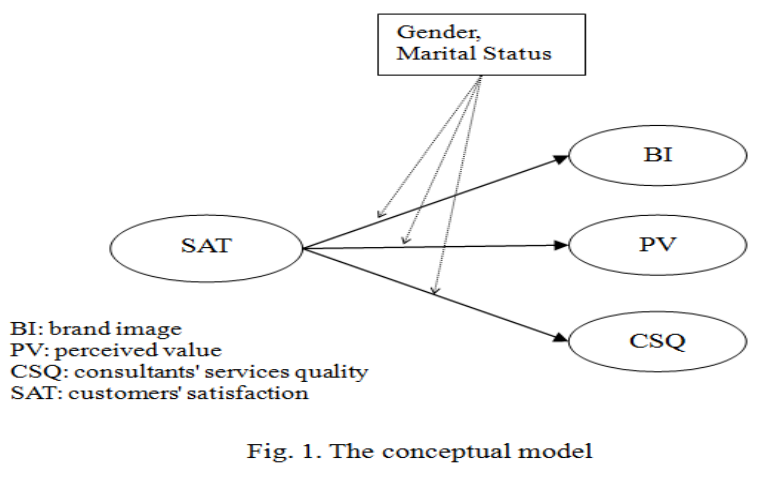




\subsection{Questionnaire}

Based on the relevant marketing research in WM services, our study uses 13 items to measure 3 dimensions including brand image (4 items), perceived value (4 items), and financial consultants' service quality (5 items), shown in Table 1. A seven-point Likert-type scale is used, with a range from one (strongly disagree) to seven (strongly agree). This study primarily uses a face-to-face interview to execute the questionnaire.

Table 1. Item Measurements for the Three Dimensions

\begin{tabular}{ll}
\hline Dimension & Item (sub-criterion) \\
\hline BI & BI1: media \\
& BI2: reputation \\
& BI3: professional \\
& BI4: social responsibility \\
\hline PV & PV1: customer differentiation \\
& PV2: acceptable fee \\
& PV3: competitive fees \\
& PV4: other competitive terms \\
\hline CSQ & CSQ1: appropriate recommendation \\
& CSQ2: abundant experience \\
& CSQ3: speedy response \\
& CSQ4: friendliness \\
& CSQ5: more benefit offering \\
\hline
\end{tabular}

BI: Bank Image; PV: Product Value; CSQ: Consultants' Service Quality.

We executed two-stage questionnaire. In first-stage questionnaire, three dimensions consisting of 13 items were used to ask EMBA students. The obtained quantitative data was employed by an EFA to measure factors influencing customers' selection of WM services. In second-stage questionnaire, the items yielded by the EFA results were deployed to questionnaire again through three WM providers over the period January 2012-March 2012. Afterward, the respondents obtained from the second-stage questionnaire were used to identify the results of the EFA by a CFA.

\section{Empirical Results}

\subsection{Results of Exploratory Factor Analysis}

We used 196 respondents and 13 items to identify a concise set of factor constructs. After few times extracting, the value of Bartlett's test of sphericity is 970.192 and significant at the $1 \%$ level, which is used to assess the overall significance of the correlation matrix. In addition, the value of the Kaiser-Meyer-Olkin (KMO) is 0.842 , which indicates that the variables meet the fundamental requirements for factor analysis (Hair et al. 1998). Therefore, the sample and correlation matrix are appropriate for the analysis. As results, a 3-factor 9-item measurement model is obtained in terms of consultants' service quality (CSQ), perceived value (PV), and brand image (BI). It accounts for $71.961 \%$ of the variance; the explained variances for CSQ, PV, and BI, are $27.836 \%$, $22.655 \%$, and $21.469 \%$, respectively. The first factor did not account for a majority of the variance. Therefore, the common method variance is not a significant issue herein (Tu et al., 2011).

In the CSQ construct, customers require consultants' speedy response, benefits offering, abundant experience, and appropriate recommendation. In the PV construct, customers focus on competitive fees, competitive terms, and customer differentiation. In the BI construct, customers rely on WM providers' reputation and professional to select WM services. We then use the 9 items to questionnaire and identify if the three factors influence customers' WM services again.

\subsection{Results of Confirmatory Factor Analysis}

The second-order CFA model reveals that the second-order factor can be explained by the first-order factors: BI (brand image), PV (perceived value), and CSQ (consultants' service quality). Some studies argue that brand image influences customers' trust and hence improves customers' satisfaction with banks' services (de Chernatony and Dall'Olmo Riley, 1999). In addition, previous studies have indicated that brand image, perceived value, and service quality are associated with customers' satisfaction (Soureli et al. 2008; Yu and Ting, 2011). Therefore, we name the second-order factor as SAT (satisfaction), which can represent overall customers' satisfaction with WM services. Figure 2 shows the results of the second-order CFA.

The value of the chi-squared statistic divided by the degree of freedom is 2.87 , which is less than the threshold value of 3 . The value of RMSEA is 0.066 , less than the threshold value of 0.085 . Furthermore, referring to the other fit statistics, all indices are above a common threshold value. This implies that the estimated model is valid (Hair et al., 1998).

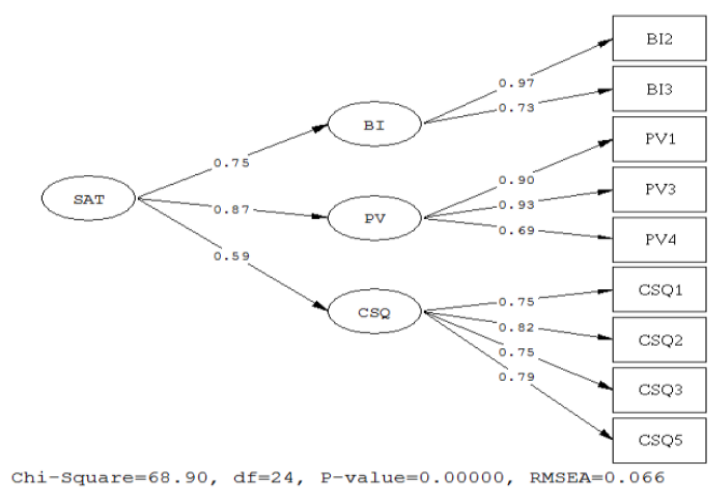

Fig. 2. A second-order CFA of WM services 
Table 2 reports the results of validity and reliability. Each factor loading of the construct factors shows highly significant t-statistics, which implies that all observed variables provide good measures to their respective factor construct in the proposed model (Anderson and Gerbing, 1988). Average variance extracted (AVE) evaluates the amount of variance captured by the construct. Thus, AVE that is larger than 0.5 indicates the measurement error is less than the variance captured by the construct. Composite reliability $(\mathrm{CR})$ reflects the internal consistency of the indicators measuring each construct. Moreover, all the AVE values are over the recommended value of 0.5 , and all the values of $\mathrm{CR}$ are over common threshold of 0.7. In addition, Table 3 reveals that the root square value of AVE for each construct is greater than the squared correlations between the construct, indicating that each construct was a distinct construct (Hair et al. 1998).

Table 2. Test results of validity and reliability

\begin{tabular}{l|llll}
\hline Factor & Observed variable & Factor loading (t-value) & AVE & CR \\
\hline BI & BI2: reputation & $0.97^{1}$ & 0.74 & 0.85 \\
& BI3: professional & $0.73\left(12.33^{* * *}\right)$ & & \\
PV & PV1: customer differentiation & 0.90 & 0.72 & 0.88 \\
& PV3: competitive fees & $0.93\left(26.05^{* * *}\right)$ & & \\
CSQ & PV4: other competitive terms & $0.69\left(16.48^{* * *}\right)$ & & \\
& CSQ1:appropriate recommendation & 0.75 & 0.61 & 0.86 \\
& CSQ2:abundantexperience & $0.82\left(16.87^{* * *}\right)$ & & \\
& CSQ3:speedy response & $0.75\left(14.80^{* * *}\right)$ & & \\
& CSQ5:more benefits offering & $0.79\left(15.56^{* * *}\right)$ & & \\
\hline
\end{tabular}

${ }^{1}$ : Since the first observed variable of each factor is used to standardize the other factor loadings in the same factor, its t-value does not exist. ${ }^{* * *}$ : significance at $1 \%$ level. BI: Bank Image. PV: Perceived Value. CSQ: Consultants' Service Quality.

Table 3. Results of discriminant validity analysis

\begin{tabular}{c|ccc}
\hline & BI & PV & CSQ \\
\hline BI & $\mathbf{0 . 8 6 ^ { * }}$ & & \\
PV & 0.65 & $\mathbf{0 . 8 5}$ & \\
CSQ & 0.44 & 0.51 & $\mathbf{0 . 7 8}$
\end{tabular}

*: The diagonal values represent the root square of average variance extracted (AVE) for each construct. Non-diagonal values are the correlation square between the construct.

Path coefficients, standardized total effects of exogenous latent variables (i.e., one second-order factor: SAT) on endogenous latent variables (i.e., three first-order factors: BI, PV, and CSQ), are used to assess whether the proposed relationships are substantiated. Table 4 shows that all path coefficients between a second-order factor and three first-order factors are statistically significant. The path coefficients for BI, PV, and CSQ are 0.75, 0.87, and 0.59, respectively, which implies that the three first-order factors can account for the second-order factor due to significant and high path coefficients. Thus, three hypotheses could not be rejected. Three first-order factors: brand image, perceived value, and financial consultants' service quality are key dimensions for customers' selection of WM services, and the second-order factor can be used to represent customers' overall satisfaction with WM services.

In the BI construct, we find that customers rely on WM providers' reputation and professional to select WM services. This is because the specific function of the brand as a risk-reducing device through the trust it conveys (de Chernatony and Dall'Olmo Riley, 1999). During the 2008 financial crisis, customers accused their WM providers because of unclear explanation and demonstration about investment risks associated with structured products, which resulted in their huge loss. To robust and retrieve brand image, WM providers should minimize negative opinion from customers and improve employee's professional. In the PV construct, three items are identified again, which shows that customers prefer to obtain competitive fees, competitive terms, and customer differentiation (added value services). This reveals price strategies are important for WM providers to attract customers. High net worth individuals are more likely to obtain upscale (differentiated) better services. In the CSQ construct, customers require consultants' speedy response, benefits offering, abundant experience, and appropriate recommendation are identified by the CFA approach again. The path coefficient of CSQ is less than those of BI and PV, which may imply that the financial crisis in 2008 weakens the "guan-xi" between financial consultants and customers.

In sum, the results of EFA and CFA suggest the three hypotheses that is BI, PV, and CSQ influence customers' selection of WM services. The results of EFA show that CSQ might be the most important factor that influences customers' selection of a WM provider, and those of the second-order CFA show that PV is the most significant factor influencing customers' overall satisfaction with WM services. This implies that CSQ is the basic requirement while PV is the best way to win the WM market.

Table 4. Results of path relationship

\begin{tabular}{lcc}
\hline Path relationship & Path coefficient & t-value \\
\hline IS $\rightarrow$ BI & 0.75 & $14.62^{* * *}$ \\
IS $\rightarrow$ PV & 0.87 & $15.09^{* * *}$ \\
IS $\rightarrow$ CSQ & 0.59 & $8.78^{* * *}$ \\
\hline${ }^{* * *}:$ significance at 1\% level. BI: Bank Image. PV: Perceived Value. CSQ: \\
Consultants'Service Quality.
\end{tabular}

For executing the moderating effects analysis, the 
suggested model is carried out for each group. The values of RMSEA for male, female, married, and single groups are $0.058,0.080,0.076$, and 0.062 , respectively. All the RMSEA values are less than the threshold value of 0.85 , which implies that the data-model fit is appropriate for each group. The path coefficients of the female (single) group are set to be equal to the male (married) group, and the estimation procedure is carried out again. A new chi-square statistics of the male (married) group is obtained and then is compared with the original chi-square of the male (married) group. If the incremental amount of chi-square is significant, the moderating effects exist (Johnson, 1999). The incremental amount of chi-square for the male (married) group is 4.78 (8.42), less (larger) than $X^{2}{ }_{0.05,3}(=7.815)$, which implies that the moderating effect in marital status is significant while that in gender is not.

Furthermore, as shown in Table 5, the total effects in male and female groups are 2.21 and 2.22, respectively, which implies that there is no difference between male and female groups. However, the total effect in single group (2.31) is slightly greater than that in married group (2.19). This result reveals that there may be difference between single and married groups, which is consistent with the result mentioned above based on the test of incremental amount of chi-square. The effect of BI on SAT is greater in single group, which implies that single people more focused on brand image. In addition, the effect of CSQ on SAT is greater in married group, which implies that married people are more emphasize on consultants' service quality.

Table 5. Summary of moderating effects

\begin{tabular}{l|cccc}
\hline \hline \multirow{2}{*}{ Path relationship } & Male $(\mathrm{N}=184)$ & Female $(\mathrm{N}=243)$ & Married $(\mathrm{N}=265)$ & Single $(\mathrm{N}=162)$ \\
& RMSEA $=0.058$ & RMSEA $=0.086$ & RMSEA $=0.076$ & RMSEA $=0.062$ \\
\hline \hline $\mathrm{BI} \rightarrow \mathrm{SAT}$ & $0.73^{* * *}(11.5)$ & $0.77^{* * *}(9.16)$ & $0.71^{* * *}(11.72)$ & $0.98^{* * *}(9.56)$ \\
$\mathrm{PV} \rightarrow \mathrm{SAT}$ & $0.87^{* * *}(12.25)$ & $0.88^{* * *}(9.26)$ & $0.87^{* *}(12.64)$ & $0.84^{* * *}(7.92)$ \\
$\mathrm{CSQ} \rightarrow \mathrm{SAT}$ & $0.61^{* * *}(7.10)$ & $0.55^{* * *}(5.44)$ & $0.61^{* * *}(7.51)$ & $0.49^{* * *}(4.00)$ \\
Total effect & 2.21 & 2.22 & 2.19 & 2.31 \\
\hline \hline
\end{tabular}

\section{Conclusion Remark and Strategies Implications}

\subsection{Conclusion Remark}

According to our study results, we suggest a second-order CFA model, in which three first-order factors: brand image, perceived value, and consultants' quality service can account for the second-order factor, i.e., customers' overall satisfaction with WM services. We find that customers mainly rely on brand image consisting of financial institutions' reputation and professional to select a
WM provider. Customers feel higher perceived value from competitive fees, competitive terms, and customer differentiation. In addition, they expect that financial consultants can provide prompt services, benefits offering, abundant experience, appropriate product recommendation. The moderating analysis results show that there exist differences between married group and single group.

\subsection{Strategic Implications}

Our study results reveal that brand image is a key factor influencing customers, especially single people to select a WM provider. For the potential customers who are looking for a WM provider, we would like to suggest them not to choose one just base on the brand image. This type of selecting process implies that customers use heuristic to make decisions. Behavioral finance points out that heuristic is the fast and frugal way to make investment decisions and it considered as a cognitive bias. This can be dangerous particularly while the new financial products being created day by day, the risk can be varies and unknown. Without truly understand the features and the rules of the products, customers can loss more than they can image.

On the other hand, financial institutions should improve their brand image if customers continuously use heuristic to select a WM provider. To strengthen brand image and maximize the power through word-of-mouth, WM providers should minimize negative opinions from customers and improve employees' professional. Moreover, since competitive prices and terms are the items that determine customers' perceived value, WM providers should obviously disclosure service charges and offer competitive fees to increase customers' utility. Furthermore, financial consultants should rapidly inform customers about their investment results when financial markets reverse. This can minimize customers' losses. Customers prefer that financial consultants have abundant experience and knowledge to recommend appropriate products for them. In order to achieve this objective, consultants first should periodically take in-job training and continuous education. When they understand the markets and the products more, they would be able to explain or demonstrate the level of risk much more clear to their customers. Second, they should try their best to get to know their customers. The right products can only be recommended when they truly understand customers' preference and characteristics. The last but not at least, if the consultants can treat their customers as their family, they will be able to provide sincere suggestion and recommendation. In this way, they 
will be able to create a long term relationship and remain customers' loyalty.

According to customers' claim, the main cause of 2008 financial crisis is because WM providers did not truly demonstrate the risk level of those financial products. Therefore, regulatory authorities can contribute in this issue by creating a less information asymmetry environment. This can be done by new regulation to enforce WM providers to disclose full set of information. For instance, Sarbanes-Oxley Act in accounting improves information disclosure. Furthermore, creating a set of rule that can lawfully investigate any disputed transactions or activities, so investors can be better protected. This is particularly important for small investors since they do not have any resources to fight against those big WM providers. Government needs to act correctly at right time. Only when the markets with impeccable rule and regulations, proprietors are more willing to practice self-discipline.

\section{References}

(1) Al-Hawari Mohammed, Nicole Hartley, and Tony Ward: "Measuring banks automated service quality: A confirmatory factor analysis approach", Marketing Bulletin, Vol. 16, No. 1, pp. 1-19, 2005.

(2) Anderson James C. and David W. Gerbing: "Structural equation modelling in practice: A review and recommended two stage Approach", Psychological Bulletin, Vol. 27, No. 1, pp. 5-24, 1988.

(3) Barber Brad M. and Terrance Odean: "All that glitters: the effect of attention and news on the buying behavior of individual and institutional investors Studies", The Review of Financial Studies, Vol. 21, pp. 1-34, 2008.

(4) Chan Carlson and Andrew Chan: "Attitude toward wealth management services: Implications for international banks in China", International Journal of Bank Marketing, Vol. 29, No. 4, pp. 272- 292, 2011.

(5) Chang Jerry Cha-Jan, Gholamreza Torkzadeh, and Gurpreet Dhillon: "Re-examining the measurement models of success for internet commerce", Information Management, Vol. 41, pp. 577-584, 2004.

(6) de Chernatony Leslie and Francesca Dall'Olmo Riley: "Experts' views about defining services brands and the principles of services branding", Journal of
Business Research, Vol. 46, Issue 2, pp. 181-192, 1999.

(7) de Chernatony, Leslie. and Susan Cottam: "Internal brand factors driving successful financial services brands", European Journal of Marketing, Vol. 40, No. 5/6, pp. 611 - 633, 2006.

(8) Filbecka, Greg, Gorman Raymond, and Zhao Xin: " Barron's most respected companies", Accounting and Finance, Vol. 53, Issue 3, pp. 623-641, 2013.

(9) Hair Joseph F., Rolph E. Anderson, Roland L. Tatham, and Willam C Black: "Multivariate Data Analysis", 5th Edition, Upper Saddle River, New Jersey, Prentice Hall, 1998.

(10) Johnson Jean L.: "Strategic integration in industrial distribution channels: managing the inter-firm relationship as a strategic asset", Journal of the Academy of Marketing Science, Vol. 27, No. 1, pp. 4-18, 1999.

(11) Keller Kevin Lane: "Conceptualizing, measuring customer-based brand", Journal of Marketing, Vol. 57, No. 1, pp. 1-23, 1993

(12) Li Fuan, Nan Zhou, Rajiv Kashyap, and Zhilin Yang: "Brand trust as a second-order factor: An alternative measurement model", International Journal of Market Research, Vol. 50, No. 6, pp. 817-839, 2008

(13) Mudambi Susan MacDowell, Peter Doyle, and Veronica Wong: "An exploration of branding in industrial markets", Industrial Marketing Management, Vol. 26, No. 5, pp. 433-446, 1997.

(14) Parasuraman, A., V. A. Zeithaml, , and L. Berry: " SERVQUAL: A multiple-item scale for measuring consumer perceptions of service quality", Journal of Retailing, Vol. 64, No.1, pp. 12-40, 1988).

(15) Smith Katherine Taken, Murphy Smith, and Kun Wang: "Does brand management of corporate reputation translate into higher market value?", Journal of Strategic Marketing, Vol. 18, No. 3, pp. 201-221, 2010.

(16) Soureli Magdalini, Barbara R. Lewis, and Kalipso M. Karantinou: "Factors that affect consumers' cross-buying intention: A model for financial services", Journal of Financial Services Marketing, Vol. 13, No.1, pp. 5-16, 2008.

(17) Statman Meir, Kenneth L. Fisher, and Deniz Anginer: "Affect in a behavioral asset pricing model", Financial Analysts Journal, Vol. 64, No. 2, pp. 20-29, 2008.

(18) Thaler Richard H: "Mental Accounting and 
Consumer Choice", Marketing Science, Vol. 4, pp. 199-244, 1985.

(19) Tu, Teng-Tsai, Chang, Hsin-Hue, and Yung-Ho Chiu: "Investigation of the factors influencing the acceptance of electronic cash stored-value cards", African Journal of Business Management, Vol. 5, No. 1, pp. 108-120, 2011.

(20) $\mathrm{Yu}$ Vincent F. and Hsiu-I Ting: "Identifying key factors affecting consumers' choice of wealth management services: An AHP approach", The Service Industrial Journal, Vol. 31, No. 6, pp. 929-939, 2011.

(21)Zeithaml Valarie A.: " Consumer perceptions of price, quality, and value: A means-end model and synthesis of evidence", Journal of Marketing, Vol. 52, pp. 2-22, 1988. 